\title{
FASTING TECHNIQUES - CHANGING THE WAY, YOU LOOK AT THERAPY
}

\author{
TANUDEEP DATTA, MOHAMMAD AZAMTHULLA*
}

Department of Pharmacology, Faculty of Pharmacy, M. S. Ramaiah University of Applied Sciences, Bengaluru, Karnataka, India. Email: mohammadazamthulla@gmail.com

Received: 22 January 2020, Revised and Accepted: 02 March 2020

ABSTRACT

At present, various complications such as diabetes, cardiovascular diseases, cancer, and neurological disorders have become treatable, almost completely, but the drugs used for the treatment may cause some severe side effects such as hypoglycemia, kidney complications, diarrhea, anemia, rashes, dyskinesia, insomnia, hypotension, confusion, hallucinations, compulsive behavior, and neurological complications. Some treatments cause defects in whole organ systems including damage to the immune system, lungs, heart, nerve endings, and reproductive organs. Many treatment approaches are using non-pharmacological techniques for treating diseases, without synthetic drugs. One such technique is fasting, a process where starvation conditions are imitated voluntarily. Intermittent fasting is done in ratios of fasting and food intake, where a person deprives himself of food for $16 \mathrm{~h}$ and food intake is followed for the rest of $8 \mathrm{~h}$. Alternate day fasting includes alternate days of food intake and fasting. Time-restricted feeding is done by allowing food consumption only during the metabolically active phase of the day. Fasting mimicking diet is done by reducing food intake to very small levels which mimics the conditions of fasting. Reported beneficial effects of fasting have been found in diseases such as cancer, blood pressure disorders, autoimmune diseases, fibrosis, inflammation, insulin sensitivity, and oxidative stress.

Keywords: Time-restricted feeding, Fasting mimicking diet, Caloric restriction, Dietary restriction.

(C) 2020 The Authors. Published by Innovare Academic Sciences Pvt Ltd. This is an open access article under the CC BY license (http://creativecommons. org/licenses/by/4. 0/) DOI: http://dx.doi.org/10.22159/ajpcr.2020.v13i5.36910

\section{INTRODUCTION}

In this fast-paced scientific world of today, there has been development and innovation of unimaginable scale. In the field of medical sciences, such developments have found a complete cure for many untreatable diseases; using medicines are researched on with great detail. Today, there is hardly any medical complication that cannot be treated, at least to some extent. However, with great innovations come great risks and the same has been happening all over the world. The techniques, the drugs, the chemicals, etc., even though they are highly effective, come with a lot of side effects, adverse effects, other related complications, and even creating unimaginably painful situations which sometimes even lead to death.

The human body is very complex, and hence there is a whole dimension of problems related to it. However, as a matter of fact, it has defense mechanisms to treat, cure, and prevent itself from almost all such problems. We ignore this fact and force our approach of treatment through the unnatural ways of drugs and other such treatment approaches such as laser therapy, and radiation therapy. We do not allow our bodies to use their defense mechanisms. One such mechanism is "Fasting." It is a process where starvation conditions are imitated voluntarily. Fasting is something that has its roots in every culture, every religion, every country, and almost every human being has practiced fasting in one or the other way, at some point in their life.

In a natural process, all cells are programmed to act in a certain way but under various types of stress conditions they tend to change and defend themselves against that stress, fasting is one such stress (Fig. 1). It has been seen that fasting has beneficial effects on the health of an individual and also during medical complications. This review is all about the beneficial effects of fasting on the health of an individual by acting on various organs, organ systems, tissues, and even at the cellular level. Fasting, when done in a calculated and well-monitored way, has tremendous effects on health. The solutions to the most complex problems are always the simplest ones.

Fasting is classified based on the various parameters such as the period of food deprivation, and the amount of food intake.
1. Intermittent fasting (IF)

2. Alternate day fasting (ADF)

3. Time-restricted feeding

4. Dietary restriction (DR)

5. Fasting mimicking diet (FMD)

6. Calorie restriction (CR)

7. Limited daily feeding (LDF).

IF

IF is the most widely followed type of fasting and it has many subtypes in itself. IF is done in ratios of fasting and food intake like 16:8 where a person deprives himself of food for $16 \mathrm{~h}$ and food intake is followed for the rest $8 \mathrm{~h}$ of the day. Sometimes the $16 \mathrm{~h}$ of fasting are followed overnight or throughout the day [1]. Sometimes the IF can go up to $48 \mathrm{~h}$ long fasting time and a smaller period of normal food intake. It was seen that the animals tend to eat more in the food intake hours and hence maintain normal body weight as they are ingesting a similar amount of food as of the ones kept without fasting. IF also has an effect on increasing growth hormone levels if followed compliantly for long periods of time but at the same time it has been seen to have side effects, chronic IF of more than $4-5$ months is not suggested [2,3].

In a few studies, done on rats it has been observed that IF results in reduced myocardial damage due to ischemia. A study was done, where myocardial infarction (MI) was induced by coronary artery ligation, there was a significant reduction in the damage due to ischemic injury. A two-fold reduction in MI size and a four-fold reduction in apoptotic myocytes were observed in the intermittent fasted group when compared with the control group. Left ventricular remodeling and MI expansion were seen in the control animal but it was totally absent in the intermittently fasted animals after 10 weeks of induction of MI. They also observed better left ventricular function and no MI expansion in a subgroup at the 1-week period from the induction of MI $[1,4]$.

The mechanism of IF in cardio-protection is largely unknown but few assumptions were made about the mechanism that include involvement of reduced free radical production and improvement in the cellular stress response, focusing on the fact that IF is similar to 


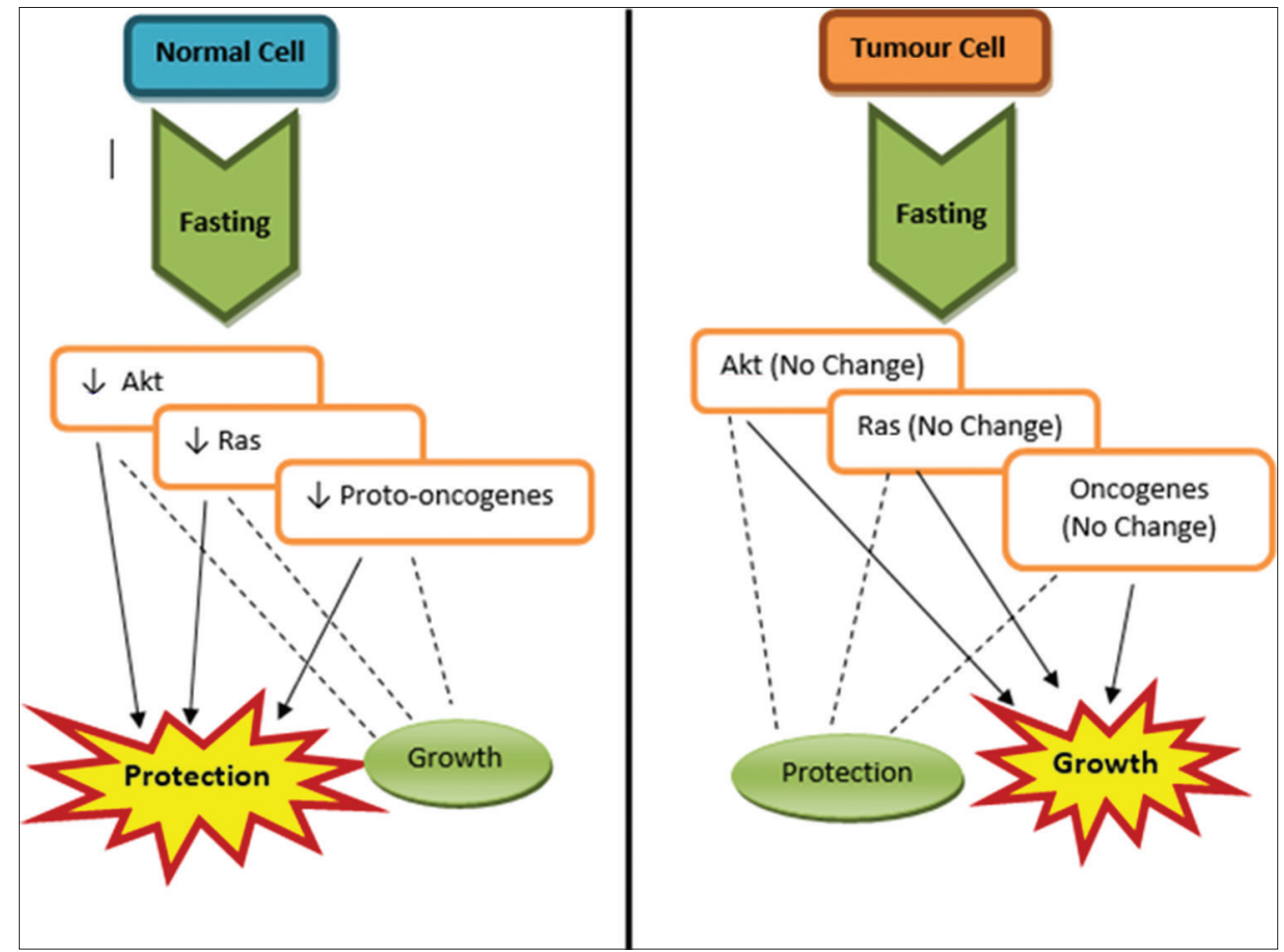

Fig. 1: Normal cells lead to specific changes during fasting leading to better protection and minimal growth while cancer cells do not change at all and hence, they do not get protected against chemotherapy which leads to their destruction

a mild stress given repeatedly on an everyday basis, hence inducing expression of genes that enhance the ability of the cells to protect themselves in situations with higher stress conditions like that of MI [5]. This assumption was supported with few pieces of evidence like IF initiated induction of the expression of protein chaperones, like glucose-regulated protein-78, and the heat shock protein-70 with few growth factors [6]. Caloric restrictions and various types of fasting techniques help in conditions such as obesity, high blood pressure (BP), and high lipid levels which eventually contribute to complications such as MI and eventually lead to cardiac heart failure [4,7].

IF has beneficial effects in high-fat diet animals such as they increase the metabolic rate and energy intake in such animals, which shows that it also reduces fat due to high energy intake for weight loss programs [8,9]. It reduces body weight and reduces fat pads in the gonadal and inguinal areas of the experimental animals. Furthermore, in a study, it showed to have altered the renin-angiotensin-aldosterone system and hence, exerted beneficial metabolic effects on BP and cardiac structure on high fat-fed or high fructose-fed mice heart $[10,11]$.

\section{ADF}

Alternative day fasting technique is alternate days of fasting with alternate days of food intake. i.e., $24 \mathrm{~h}$ of fasting and the next $24 \mathrm{~h}$ of food availability. Sometimes, this technique is confused with IF, and it actually is a type of IF but due to a 24:24 ratio, it has been named ADF [12,2]. ADF has been seen to have good therapeutic results in cardioprotection, reduced metabolic risk factors, cardiovascular diseases, and mostly age-related complications $[13,4]$.

In 2009, few scientists in Italy studied the effect of ADF on rat heart. The ADF gave significant protection to the heart from age-induced inflammation and fibrosis. The age-related oxidative damage was demonstrated by increased HNE content and protein carbonyl levels, this was accompanied by a decrease in reduced glutathione (GSH), increased oxidized GSH [GSSG], and decreased GSH/GSSG ratio [14]. The above said changes were restored almost entirely by ADF, as the levels were brought to the levels very similar to that of animals as young as 6 months of age $[15,16]$.
There was a significant increase in tumor growth factor-(TGF)- $\beta 1$ and interstitial collagen deposits at animals aged around 24 months. After the ADF regimen, the animals showed reduced levels of TGF- $\beta 1$, close to that of 12 months aged animals and the collagen deposit levels were lowered even further to the levels of 6-month animals. Interleukin (IL$6)$, IL-1 $1 \beta$, and tumor necrosis factor (TNF)- $\alpha$, the pro-inflammatory cytokines were also examined to compare the inflammatory parameters as their levels also change significantly on aging. TNF- $\alpha$ and IL-6 levels were seen at increased levels at 12 months of age, while IL- $1 \beta$ was seen to have increased levels only at 24 months of age. ADF showed protection against this increase, it was seen more effectively for TNF- $\alpha$ and IL-6 as it went down to levels close to 6-month aged animals and IL-1 $\beta$ was reduced close to the young levels too $[17,18]$. Nuclear factor kappa-light-chain-enhancer of activated B cells (NF- $\mathrm{KB}$ ) is a protein complex that has a great role in the transcription of deoxyribonucleic acid (DNA) and cytokine production. This factor is sensitive to stress conditions, cytokines, free radicals, etc., and functions greatly in cell survival. Hence, this factor was also considered for this study and it was found that there was a marked age-related increase in the DNA binding activity of this factor in the heart, starting at age 12 months itself. Although ADF nullified the symptoms of the diseases but also showed synergist action with the therapeutic drugs in the treatment of diseases [16].

Now this, fasting technique can be followed acutely for a short period of time like few days, a week or it can be continued for long periods like months together, then it is called chronic ADF. In a study, they specifically showed that the effect of alternate-day fasting in agerelated complications such as fibrosis and age-induced inflammation and very good results was obtained the fasting almost nullified the harmful effects of age on the heart of rats $[19,16]$.

\section{Time-restricted feeding (TRF)}

Time restriction feeding is a form of fasting where food consumption is followed only during the metabolically active phase of the day. This sort of diet leads to better metabolic parameters when a high-fat diet is being followed [20]. This type of fasting helps to reduce maternal 
high fat diet-associated inflammation and hence also in reducing fetal birth defects [21,22].

This type of fasting has a special type of beneficial effect. Time being a factor in this process leads to treating conditions related to biological clock defects [23]. Circadian rhythm impairment can cause serious metabolic complications such as obesity and other metabolic diseases [24]. In such situations, when time-restricted feeding is provided, i.e., food available only during $10 \mathrm{~h}$ of the dark phase, then it showed reduction in the complications due to circadian rhythm impairment $[25,26]$. Even in case of skin complications caused by skin circadian clock defect, it was seen to alter the ultraviolet-B induced DNA damage $[23,27,28]$.

TRF has been observed to have an improved effect on insulin sensitivity, $\beta$ cell responsiveness, $\mathrm{BP}$, oxidative stress, and appetite when followed during the healthy state $[29,20]$. TRF even influences the immune response without causing any damage to the muscle performance [30,31].

\section{DR}

This is a type of restriction where the food intake or specific components in food are restricted or reduced for short or long periods [32]. Those components comprise the major dietary constituents such as proteins, lipids, and carbohydrates. This type of restriction is used in experimental animals such as rodents for protection against age-related complications, cancer incidence, and other medical complications such as atherosclerosis, inflammatory conditions, Alzheimer's disease, tumors, and other chronic degenerative diseases. [33,34].

Some studies have even shown attenuation of infection by DR, in the same study they also observed that DR can cause alteration in insulinlike signaling and also help in increasing life span [35].

In a different study done on C57BL/6 mice, where the animals were kept on DR and the results obtained showed that IF caused an increased insulin sensitivity, stress resistance, reduced morbidity, and increased life span. The mechanism for the treatment of various diseases by fasting technique methods are not clearly known, but hypothesis says that long term reduction in food intake/calorie intake is essential for more effective treatment [36,37]. When the mice were kept for IF/ADF their total food intake when compared to the ad libitum (AL) fed animals the same as that of the AL fed mice [38]. This shows that when the DR mice were allowed free access to the food then they ate almost twice the amount of food than the AL fed mice. Hence, the calorie intake was almost the same for both mice groups and hence even their body weight change was not that much. DR fasting though showed more benefits than the caloric restriction group $[39,40]$.

The overall conclusion was that DR fasting has beneficial effects on glucose regulation and neuronal resistance to injury in these mice that are independent of caloric intake [38].

\section{FMD}

This type of fasting usually lasts for short periods of time, here instead of actually abstaining from food, the food intake is reduced to very small levels which mimics the conditions of fasting but does not abstain the body completely from the food intake hence prevents some side effects which can be caused due to prolonged effects of strict fasting $[8,41]$. This type of mimicking diet has shown the effects of enhancing the microbiota growth in the intestine, which reduces the pathology of irritable bowel disease greatly [42].

FMD and a special type of nutrition could be used for treating autoimmune diseases and immunosenescence, i.e., natural deterioration of the immune system brought on by normal aging process [43]. FMD in mice during an experiment showed induction of stepwise expression of Sox17 and Pdx-1, followed by the Ngn3-driven generation of insulinproducing $\beta$ cells which reversed the diabetic effects. Hence, we can conclude that the FMD is not only beneficial for inflammatory bowel disease but also diabetes $[44,45]$.

\section{CR}

This is a type of fasting where the total number of calorie intake is reduced significantly to a specific calculated level [46]. This type of fasting is followed widely for weight loss and other physical fitness applications. Here, the food is taken time but the quantity of food is restricted to a calculated level and that level is not exceeded in a day, more than its limit $[47,48]$. CR on experimental animals was shown to increase the life span of the animals and also showed increased insulinlike growth factor (IGF)-1 levels [19,49].

Oxidative stress in any organism leads to hypertrophy of the heart and hence leading to heart failure [50]. Cardiac tissues respond to different types of stresses and hence get hypertrophied in the presence of oxidative stress [51]. However, when caloric restriction is followed it prevents the production of the reactive oxygen species and maintains enzymatic antioxidant activity [52]. Hypertrophy was seen to get reduced significantly after caloric restriction. In the process of reducing hypertrophy, a mechanism involving the activation of mitochondrial adenosine tri phosphate sensitive $\mathrm{K}^{+}$channel was involved [53,54]. Caloric restriction not only has its effects on cardioprotection and IGF-1 levels but also on psychological complications. In a study caloric restriction was seen to prevents stress-related anxiety and despair [55].

Fasting causes changes in the fundamental processes and hence has an effect on almost all body organ systems. Glucose metabolism and glucose homeostasis are also affected by various types of fasting. In a study, fasting was carried out in streptozotocin (STZ)-induced diabetic rats, the effect of the fasting was measured by the individual $\beta$-cell area and individual islet areas. Parameters such as pancreas weight, $\beta$-cell mass, apoptotic $\beta$-cells, plasma D-glucose, plasma insulin, and other tests including the intra-peritoneal glucose tolerance test (IPGTT) were considered to analyze the effects of fasting [56]. Many methods were totally followed in the study including STZ-Induced diabetes, starvation, and restricted food supply, body weight and food intake, IPGTT, insulin secretion (in-vitro), immunohistochemical study, $\beta$-cell mass assessment, glucagon immunodetection, and apoptosis detection. It was observed that IF showed significant improvement in glucose tolerance, increased plasma insulin, and lowered the homeostasis model assessment index [57].

In this same study, the data were compared between intermittently fasted animals (IF), caloric restriction (CR), and non-fasted animals (NF) without any fasting. Two major groups were made, one being the control group the other being the STZ group. The subgroups were NF, IF, and CR sub-groups. It was seen that the improvement and changes that IF showed were not observed in the case of caloric restriction [57]. An assumption can be made from this observation, that fasting does more to an organism than just starvation. Fasting needs prolonged and strict food restriction during fasting hours. Moreover, if not completely, IF can still cause significantly large prevention to the glucose homeostasis disturbances.

LDF

This type of CR technique focuses on the feeding time; hence, the feeding time or food availability hours are taken into consideration for the fasting. Hence, the food is made available for a few hours or for some times when the animals are allowed to ingest food [36]. The rest of the hours they will be left for fasting, here no specific ratio is followed. Limited daily feeding usually has significant effects on physiological parameters such as body temperature, heart rate, BP, and decreased glucose and insulin levels [58].

Limited daily feeding was seen to have a significant effect on the brain and its activity. The effect is different in different parts of the brain it was shown to reduce the glucose transporter type 3 (GLUT 3) levels in the cortex region while no effect on the hippocampus region [59]. LDF 
Table 1: Fasting types with their features and results observed from various research

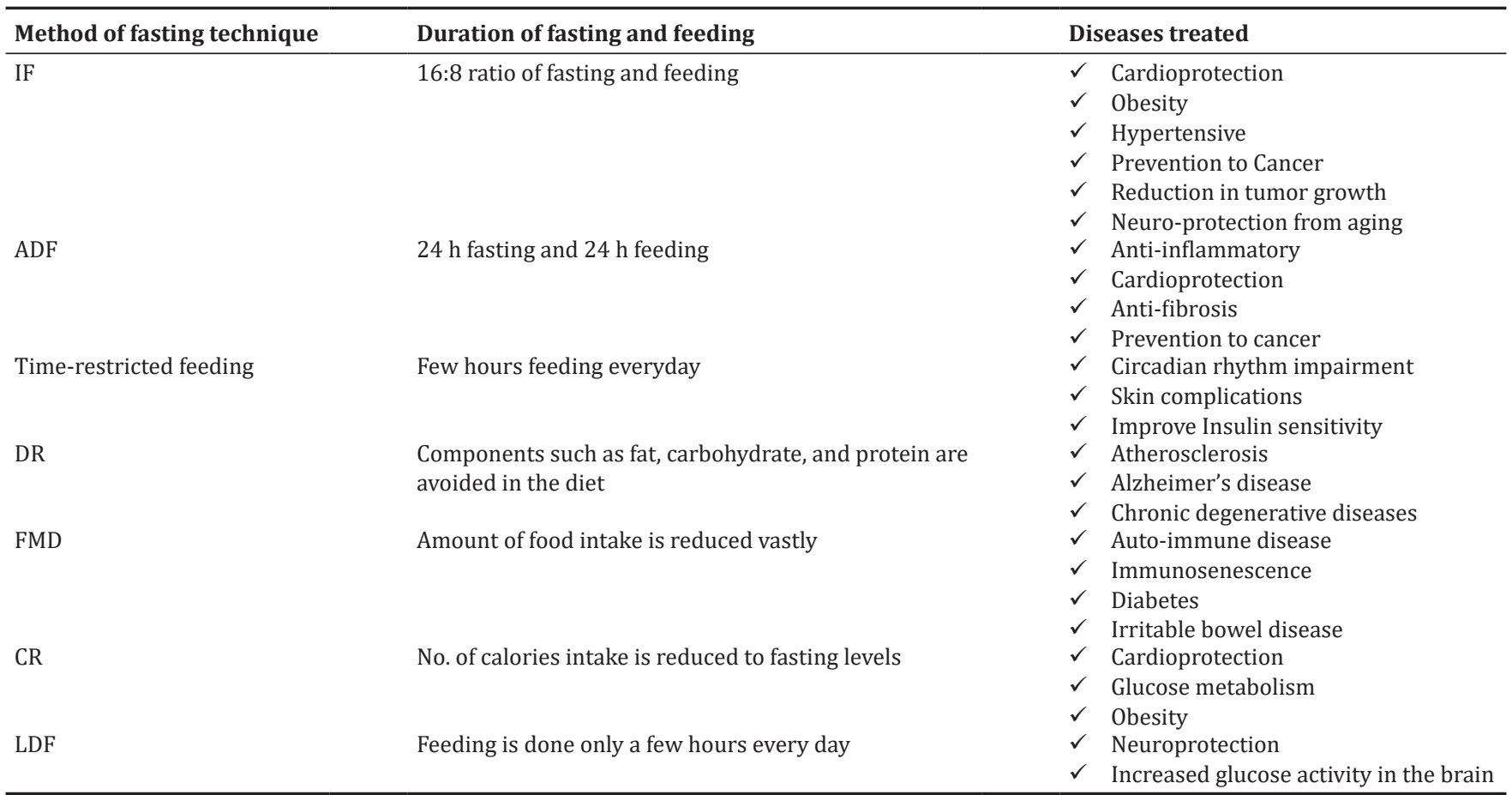

ADF: Alternate day fasting, DR: Dietary restriction, FMD: Fasting mimicking diet, CR: Calorie restriction, LDF: Limited daily feeding

in young rats showed decreasing levels of GLUT 3 but increasing levels of GLUT 3 in the aged animal. It was also seen to reduce lathosterol levels on the hippocampus and in the cortex, but only in the young animals $[60,61]$. This study suggested that age is a major factor when taking fasting into consideration. Fasting has different effects on different body parts comprising of similar cells, at different ages [62,63].

\section{Effects of fasting on cancer}

One of the major effects of fasting was seen against cancer. Few studies point toward the effect of CR type of fasting in having multiple significant effects in cancer-induced animals and tumor cell lines of various types $[64,65]$. It was seen that animals kept under restricted calorie intake, were more protected differentially against tumor growth $[66,67]$. It was also seen to have increased chemotherapeutic index for the anticancer drugs hence a huge possibility of increased potency and hence reduced dose was observed [68,69].

The growth hormone and the IGF-1 axis undergo significant changes when an organism stays in starvation conditions [70]. Growth hormones directly regulate IGF-1 production. Animals deficient in IGF-1 signaling have been seen to have much longer lives $[68,71]$.

Under normal circumstances, the organism tends to utilize the gained energy for the growth of the organism. However, under stress conditions like fasting they shift the energy utilization from growth to maintenance and hence on the cost of growing the protection of the animals is achieved [72]. Normal cells hence tend to seize their growth under starvation conditions. On the contrary, the cancer cells which are self-sufficient in growth signals, do not get affected much on starvation, as they lack growth-inhibitory signals $[73,74]$. This type of environment change leads to better protection and increased permeability of healthy cells to chemo toxic agents. Cancer cells undergo no such phenomena and hence are more prone to chemotoxicity and hence partial or differential protection and resistance to chemo toxic agents is achieved leading to protection of healthy cells and hence more toxicity on the tumor cells thereby causing death to them $[75,76]$. This type of protection toward chemotoxicity is achieved by a phenomenon called differential stress resistance achieved by healthy cells and differential stress sensitization of cancer cells. One of the mechanisms for this differential chemotherapy protection is due to the reduction in the production of IFG-1 caused by starvation $[77,78]$.

In a study, ADF was seen to increase the life span of rats inoculated with ascitic tumor cells, there was a $45 \%$ increase in survival after the animals were kept on fasting on alternate days than the animals who had food ad libitum.

Another study conducted on colon cancer showed that fasting leads to the induction of autophagy in colon cancer cells and also downregulates the adenosine levels which in return increases the M2 polarization of the tumor associated macrophages through the pathway involving JAK/STAT3. All of this leads to tumor growth suppression while stimulating antitumor immunity.

Side effects due to chemotherapy drugs are a major issue in the case of cancer treatment. Nausea and vomiting are a few of the most uncomfortable side effects caused by many anti-cancer drugs. In a study, doxorubicin related nausea and vomiting were used as a parameter to check for efficacy of fasting in controlling side effects from chemotherapeutic toxicity. Dogs were given doxorubicin treatment and were kept under fasting conditions. There was a reduction from $67 \%$ to $10 \%$ in the incidence of vomiting when the animals were kept under fasting conditions. Such significant data show that fasting not only increases the chemotherapeutic efficacy of the chemotherapeutic agent but also reduces the side effects caused by the drugs itself [79-81].

\section{CONCLUSIONS AND SCOPE}

Scientific development does not always have to be for increased use of technology but it could also be used for the reduction of its usage. Various types of fasting techniques with their duration of fasting and feeding in some of the diseases are shown in Table 1. Natural ways of treatment and prevention should be the first choice of treatment as they include no side effects, least cost, and possibly a complete cure. Technology and nature could be used in such a synchrony that the synergism of both of them gives us a side effects free, highly efficacious, 
patient compliant, user-friendly, and cost-effective treatment. Fasting is one such method that is easy and effective. Every household already follows this technique once in a while for various reasons. Now it is time to use it clinically for treatment, prevention, and management of highly dangerous diseases. When even a disease like cancer could be prevented and managed with such easy techniques then there leaves no room for the use of highly toxic and costly chemotherapy which is almost not affordable by many people. There is still a lot of space to do research in this field. Fasting techniques could also be used in various patterns to influence medical complications and hence there is still a lot of scopes left for further research in this field.

\section{AUTHOR'S CONTRIBUTION}

Collection of articles, studying the materials and preparation of this review was done by the first author. The second author reviewed the draft copy and made appropriate changes as required to form the final review paper.

\section{CONFLICTS OF INTEREST}

There were no conflicts of interest for this review paper.

\section{AUTHOR'S FUNDING}

There was no funding for this study. Minor expenses were done by the author themselves.

\section{REFERENCES}

1. Cerqueira FM, da Cunha FM, Da Silva CC, Chausse B, Romano RL, Garcia CC, et al. Long-term intermittent feeding, but not caloric restriction, leads to redox imbalance, insulin receptor nitration, and glucose intolerance. Free Radic Biol Med 2011;51:1454-60.

2. Thomas JA, Poulton S, Phillips T, Jessica C. Effect of intermittent fasting on prostate cancer and prostate cancer: Can eliminating carbohydrates. J Urol 2009;181:53.

3. Dorighello GG, Rovani JC, Luhman CJ, Paim BA, Raposo HF, Vercesi AE, et al. Food restriction by intermittent fasting induces diabetes and obesity and aggravates spontaneous atherosclerosis development in hypercholesterolaemic mice. Br J Nutr 2014;111:979-86.

4. di Biase S, Longo VD. Fasting-induced differential stress sensitization in cancer treatment. Mol Cell Oncol 2016;3:e1117701.

5. Solon-Biet SM, McMahon AC, Ballard JW, Ruohonen K, Wu LE, Cogger VC, et al. The ratio of macronutrients, not caloric intake, dictates cardiometabolic health, aging, and longevity in ad libitum-fed mice. Cell Metab 2014;19:418-30.

6. Cheng CW, Adams GB, Perin L, Wei M, Zhou X, Lam BS, et al. Prolonged fasting reduces IGF-1/PKA to promote hematopoietic-stemcell based regeneration and reverse immunosuppression. Cell Stem Cell 2014; $14: 810-23$

7. Kusuoka O, Fujiwara-Tani R, Nakashima C, Fujii K, Ohmori H, Mori T, et al. Intermittent calorie restriction enhances epithelial-mesenchymal transition through the alteration of energy metabolism in a mouse tumor model. Int J Oncol 2018;52:413-23.

8. Choi IY, Piccio L, Childress P, Bollman B, Ghosh A, Brandhorst S, et al. A diet mimicking fasting promotes regeneration and reduces autoimmunity and multiple sclerosis symptoms. Cell Rep 2016;15:2136-46.

9. Goodrick CL, Ingram DK, Reynolds MA, Freeman JR, Cider N. Effects of intermittent feeding upon body weight and lifespan in inbred mice: Interaction of genotype and age. Mech Ageing Dev 1990;55:69-87.

10. Liu B, Page AJ, Hutchison AT, Wittert GA, Heilbronn LK. Intermittent fasting increases energy expenditure and promotes adipose tissue browning in mice. Nutrition 2019;66:38-43.

11. Camelo L, de Marinho TS, Águila MB, Souza-Mello V, Barbosa-daSilva S. Intermittent fasting exerts beneficial metabolic effects on blood pressure and cardiac structure by modulating local renin-angiotensin system in the heart of mice fed high-fat or high-fructose diets. Nutr Res 2019;63:51-62.

12. Hoddy KK, Kroeger CM, Trepanowski JF, Barnosky A, Bhutani S, Varady KA. Meal timing during alternate day fasting: Impact on body weight and cardiovascular disease risk in obese adults. Obesity 2014;22:2524-31.

13. Trepanowski JF, Kroeger CM, Barnosky A, Klempel MC, Bhutani S, Hoddy KK, et al. Effect of alternate-day fasting on weight loss, weight maintenance, and cardioprotection among metabolically healthy obese adults: A randomized clinical trial. JAMA Intern Med 2017;177:930-8.

14. Klempel MC, Kroeger CM, Varady KA. Alternate day fasting (ADF) with a high-fat diet produces similar weight loss and cardio-protection as ADF with a low-fat diet. Metabolism 2013;62:137-43.

15. Catenacci VA, Pan Z, Ostendorf D, Brannon S, Gozansky WS, Mattson MP, et al. A randomized pilot study comparing zero-calorie alternate-day fasting to daily caloric restriction in adults with obesity. Obesity 2016;24:1874-83.

16. Castello L, Froio T, Maina M, Cavallini G, Biasi F, Leonarduzzi G, et al. Alternate-day fasting protects the rat heart against age-induced inflammation and fibrosis by inhibiting oxidative damage and NF-kB activation. Free Radic Biol Med 2010;48:47-54.

17. Joslin PM, Bell RK, Swoap SJ. Obese mice on a high-fat alternateday fasting regimen lose weight and improve glucose tolerance. J Anim Physiol Anim Nutr 2017;101:1036-45.

18. Bhutani S, Klempel MC, Kroeger CM, Trepanowski JF, Varady KA. Alternate day fasting and endurance exercise combine to reduce body weight and favorably alter plasma lipids in obese humans. Obesity 2013;21:1370-9.

19. Alhamdan BA, Garcia-Alvarez A, Alzahrnai AH, Karanxha J, Stretchberry DR, Contrera KJ, et al. Alternate-day versus daily energy restriction diets: Which is more effective for weight loss? A systematic review and meta-analysis. Obes Sci Pract 2016;2:293-302.

20. Greenhill C. Benefits of Time-restricted Feeding. Nat Rev Endocrinol 2018;14:626.

21. Upadhyay A, Anjum B, Godbole NM, Rajak S, Shukla P, Tiwari S, et al. Time-restricted feeding reduces high-fat diet associated placental inflammation and limits adverse effects on fetal organ development. Biochem Biophys Res Commun 2019;514:415-21.

22. Hatori M, Vollmers C, Zarrinpar A, DiTacchio L, Bushong EA, Gill S, et al. Time-restricted feeding without reducing caloric intake prevents metabolic diseases in mice fed a high-fat diet. Cell Metab 2012;15:848-60.

23. Sundaram S, Yan L. Time-restricted feeding reduces adiposity in mice fed a high-fat diet. Nutr Res 2016;36:603-11.

24. Chaix A, Zarrinpar A, Miu P, Panda S. Time-restricted feeding is a preventative and therapeutic intervention against diverse nutritional challenges. Cell Metab 2014;20:991-1005.

25. Adamovich Y, Rousso-Noori L, Zwighaft Z, Neufeld-Cohen A, Golik M, Kraut-Cohen $\mathrm{J}$, et al. Circadian clocks and feeding time regulate the oscillations and levels of hepatic triglycerides. Cell Metab 2014;19:319-30.

26. Feng D, Liu T, Sun Z, Bugge A, Mullican SE, Alenghat T, et al. A circadian rhythm orchestrated by histone deacetylase 3 controls hepatic lipid metabolism. Science 2011;331:1315-9.

27. Chaix A, Lin T, Le HD, Chang MW, Panda S. Time-restricted feeding prevents obesity and metabolic syndrome in mice lacking a circadian clock. Cell Metab 2019;29:303-19.

28. Wang H, van Spyk E, Liu Q, Geyfman M, Salmans ML, Kumar V, et al. Time-restricted feeding shifts the skin circadian clock and alters UVBinduced DNA damage. Cell Rep 2017;20:1061-72.

29. Woodie LN, Luo Y, Wayne MJ, Graff EC, Ahmed B, O’Neill AM, et al. Restricted feeding for $9 \mathrm{~h}$ in the active period partially abrogates the detrimental metabolic effects of a Western diet with liquid sugar consumption in mice. Metabolism 2018;82:1-13.

30. Sutton EF, Beyl R, Early KS, Cefalu WT, Ravussin E, Peterson CM. Early time-restricted feeding improves insulin sensitivity, blood pressure, and oxidative stress even without weight loss in men with prediabetes. Cell Metab 2018;27:1212-21.

31. Gasmi M, Sellami M, Denham J, Padulo J, Kuvacic G, Selmi W, et al. Time-restricted feeding influences immune responses without compromising muscle performance in older men. Nutrition 2018;51-52:29-37.

32. Mukherjee P, Abate LE, Seyfried TN. Antiangiogenic and proapoptotic effects of dietary restriction on experimental mouse and human brain tumors. Clin Cancer Res 2004; 10:5622-9

33. Finch CE. Energy balance, inflammation, and aging. In: The Biology of Human Longevity. Berlin: Elsevier; 2007. p. 175-232.

34. Daynes RA, Pugh TD, Ershler WB. Dietary restriction from middle age attenuates age-associated lymphoma development and interleukin 6 dysregulation in C57BL/6 mice. Cancer Res 1994;54:3054-61.

35. Mehendale HM. Role of tissue repair and death proteins in liver injury. In: Drug-Induced Liver Disease. Amsterdam, Netherlands: Elsevier Inc.; 2013. p. 195-213.

36. Barclay JL, Shostak A, Leliavski A, Tsang AH, Jöhren O, MüllerFielitz $\mathrm{H}$, et al. High-fat diet-induced hyperinsulinemia and tissuespecific insulin resistance in cry-deficient mice. Am J Physiol Endocrinol Metab 2013;304:E1053-63. 
37. Dunn SE, Kari FW, French J, Leininger JR, Travlos G, Wilson R, et al. Dietary restriction reduces insulin-like growth factor I levels, which modulates apoptosis, cell proliferation, and tumor progression in p53deficient mice. Cancer Res 1997;57:4667-72.

38. Anson RM, Guo Z, de Cabo R, Iyun T, Rios M, Hagepanos A, et al. Intermittent fasting dissociates beneficial effects of dietary restriction on glucose metabolism and neuronal resistance to injury from calorie intake. Proc Natl Acad Sci U S A 2003;100:6216-20.

39. Weinruch R, Walford RL. Dietary restriction in mice beginning at 1 year of age: Effect on life-span and spontaneous cancer incidence. Science 2012;215:1415-8

40. Weindruch R, Walford RL, Fligiel S, Guthrie D. The retardation of aging in mice by dietary restriction: Longevity, cancer, immunity and lifetime energy intake. J Nutr 1986;116:641-54.

41. Wei M, Brandhorst S, Shelehchi M, Mirzaei H, Cheng CW, Budniak J, et al. Fasting-mimicking diet and markers/risk factors for aging, diabetes, cancer, and cardiovascular disease. Sci Transl Med 2017;9:8700.

42. Rangan P, Choi I, Wei M, Navarrete G, Guen E, Brandhorst S, et al. Fasting-mimicking diet modulates microbiota and promotes intestinal regeneration to reduce inflammatory bowel disease pathology. Cell Rep 2019;26:2704-19.

43. Choi IY, Lee C, Longo VD. Nutrition and fasting mimicking diets in the prevention and treatment of autoimmune diseases and immunosenescence. Mol Cell Endocrinol 2017;455:4-12.

44. Cheng CW, Villani V, Buono R, Wei M, Kumar S, Yilmaz OH, et al. Fasting-mimicking diet promotes ngn3-driven $\beta$-cell regeneration to reverse diabetes. Cell 2017;168:775-88.

45. van Landeghem L, Blue RE, Dehmer JJ, Henning SJ, Helmrath MA, Lund PK. Localized intestinal radiation and liquid diet enhance survival and permit evaluation of long-term intestinal responses to high dose radiation in mice. PLoS One 2012;7:e51310.

46. Shelton LM, Huysentruyt LC, Mukherjee P, Seyfried TN. Calorie restriction as an anti-invasive therapy for malignant brain cancer in the VM mouse. ASN Neuro 2010;2:171-7.

47. Walford RL, Mock D, Verdery R, MacCallum T. Calorie restriction in biosphere 2: Alterations in physiologic, hematologic, hormonal, and biochemical parameters in humans restricted for a 2-year period. $\mathrm{J}$ Gerontol A Biol Sci Med Sci 2002;57:B211-24

48. Russell WR, Gratz SW, Duncan SH, Holtrop G, Ince J, Scobbie L, et al. High-protein, reduced-carbohydrate weight-loss diets promote metabolite profiles likely to be detrimental to colonic health. Am J Clin Nutr 2011;93:1062-72.

49. Fontana L, Klein S, Holloszy JO. Long-term low-protein, low-calorie diet and endurance exercise modulate metabolic factors associated with cancer risk. Am J Clin Nutr 2006;84:1456-62.

50. Mager DE, Wan R, Brown M, Cheng A, Wareski P, Abernethy DR, et al. Caloric restriction and intermittent fasting alter spectral measures of heart rate and blood pressure variability in rats. FASEB J 2006;20:631-7.

51. Fontana L, Meyer TE, Klein S, Holloszy JO. Long-term calorie restriction is highly effective in reducing the risk for atherosclerosis in humans. Proc Natl Acad Sci U S A 2004;101:6659-63.

52. Kazemi A, Speakman JR, Soltani S, Djafarian K. Effect of calorie restriction or protein intake on circulating levels of insulin like growth factor I in humans: A systematic review and meta-analysis. Clin Nutr 2019;10:1-12.

53. Barja G. Aging in vertebrates, and the effect of caloric restriction: A mitochondrial free radical production-DNA damage mechanism? Biol Rev Camb Philos Soc 2004;79:235-51.

54. David CE, Lucas AM, Araújo MT, Coelho BN, Neto JB, Portela BR, et al. Calorie restriction attenuates hypertrophy-induced redox imbalance and mitochondrial ATP-sensitive $\mathrm{K}+$ channel repression. J Nutr Biochem 2018;62:87-94.

55. Lu Y, Niu M, Qiu X, Cao H, Xing B, Sun Y, et al. Acute but not chronic calorie restriction defends against stress-related anxiety and despair in a GHS-R1a-dependent manner. Neuroscience 2019;412:94-104.

56. Tinkum KL, Stemler KM, White LS, Loza AJ, Jeter-Jones S, Michalski BM, et al. Fasting protects mice from lethal DNA damage by promoting small intestinal epithelial stem cell survival. Proc Natl Acad Sci U S A 2015;112:E7148-54.

57. Belkacemi L, Selselet-Attou G, Hupkens E, Nguidjoe E, Louchami K, Sener A, et al. Intermittent fasting modulation of the diabetic syndrome in streptozotocin-injected rats. Int J Endocrinol 2012;2012:962012.

58. Zarrinpar A, Chaix A, Panda S. Daily eating patterns and their impact on health and disease. Trends Endocrinol Metab 2016;27:69-83.

59. Wellen KE, Thompson CB. Cellular metabolic stress: Considering how cells respond to nutrient excess. Mol Cell 2010;40:323-32.

60. Sherman H, Genzer Y, Cohen R, Chapnik N, Madar Z, Froy O. Timed high-fat diet resets circadian metabolism and prevents obesity. FASEB J 2012;26:3493-502.

61. Brandhorst S, Choi IY, Wei M, Cheng CW, Sedrakyan S, Navarrete G, et al. A periodic diet that mimics fasting promotes multi-system regeneration, enhanced cognitive performance, and Healthspan. Cell Metab 2015;22:86-99.

62. Smiljanic K, Todorovic S, Djordjevic AM, Vanmierlo T, Lütjohann D, Ivkovic $\mathrm{S}$, et al. Limited daily feeding and intermittent feeding have different effects on regional brain energy homeostasis during aging. Biogerontology 2018;19:121-32.

63. Sequea DA, Sharma N, Arias EB, Cartee GD. Calorie restriction enhances insulin-stimulated glucose uptake and AKT phosphorylation in both fast-twitch and slow-twitch skeletal muscle of 24-month-old rats. J Gerontol A Biol Sci Med Sci 2012;67:1279-85.

64. Safdie FM, Dorff T, Quinn D, Fontana L, Wei M, Lee C, et al. Fasting and cancer treatment in humans: A case series report. Aging 2009;1:988-1007.

65. Premoselli F, Sesca E, Binasco V, Caderni G, Tessitore L. Fasting/ re-feeding before initiation enhances the growth of aberrant crypt foci induced by azoxymethane in rat colon and rectum. Int $\mathrm{J}$ Cancer 1998;77:286-94.

66. Doyle C, Kushi LH, Byers T, Courneya KS, Demark-Wahnefried W, Grant $\mathrm{B}$, et al. Nutrition and physical activity during and after cancer treatment: An American cancer society guide for informed choices. CA Cancer J Clin 2006;56:323-53.

67. Faber M, Coudray C, Hida H, Mousseau M, Favier A. Lipid peroxidation products, and vitamin and trace element status in patients with cancer before and after chemotherapy, including adriamycin a preliminary study. Biol Trace Elem Res 1995;47:117-23.

68. Lee C, Safdie F, Raffaghello L, Wei M. Reduced IGF-I differentially protects normal and cancer cells and improves chemotherapeutic index in mice. Cancer Res 2010;70:1564-72.

69. Bonorden MJ, Rogozina OP, Kluczny CM, Grossmann ME, Grambsch PL, Grande JP, et al. Intermittent calorie restriction delays prostate tumor detection and increases survival time in TRAMP mice. Nutr Cancer 2009;61:265-75.

70. Hursting SD, Lavigne JA, Berrigan D, Perkins SN, Barrett JC. Calorie restriction, aging, and cancer prevention: Mechanisms of action and applicability to humans. Ann Rev Med 2003;54:131-52.

71. Bartke A. Minireview: Role of the growth hormone/insulin-like growth factor system in mammalian aging. Endocrinology 2005;14:3718-23.

72. Shanley DP, Kirkwood TB. Calorie restriction and aging: A life-history analysis. Evolution 2000;54:740-50.

73. Berrigan D. Adult-onset calorie restriction and fasting delay spontaneous tumorigenesis in p53-deficient mice. Carcinogenesis 2002;23:817-22.

74. Kritchevsky D. Caloric restriction and cancer. J Nutr Sci Vitaminol 2001;47:13-9.

75. Raffaghello L, Lee C, Safdie FM, Wei M, Madia F, Bianchi G, et al. Starvation-dependent differential stress resistance protects normal but not cancer cells against high-dose chemotherapy. Proc Natl Acad Sci U S A 2008; 105:8215-20.

76. Siegel I, Liu TL, Nepomuceno N, Gleicher N. Effects of short-term dietary restriction on survival of mammary ascites tumor-bearing rats. Cancer Investig 1988;6:677-80.

77. Lee C, Longo VD. Fasting vs dietary restriction in cellular protection and cancer treatment: From model organisms to patients. Oncogene 2011;30:3305-16.

78. Sun $\mathrm{P}$, Wang $\mathrm{H}, \mathrm{He} \mathrm{Z}$, Chen $\mathrm{X}$, Wu Q, Chen $\mathrm{W}$, et al. Fasting inhibits colorectal cancer growth by reducing M2 polarization of tumorassociated macrophages. Oncotarget 2017;8:74649-60.

79. Withers SS, Kass PH, Rodriguez CO, Skorupski KA, O’Brien D, Guerrero TA, et al. Fasting reduces the incidence of delayedtype vomiting associated with doxorubicin treatment in dogs with Lymphoma. Transl Oncol 2014;7:377-83.

80. Buschemeyer WC, Klink JC, Mavropoulos JC, Poulton SH, DemarkWahnefried W, Hursting SD, et al. Effect of intermittent fasting with or without caloric restriction on prostate cancer growth and survival in SCID mice. Prostate 2010;70:1037-43.

81. Hursting SD, Perkins SN, Phang JM, Barrett JC. Diet and cancer prevention studies in p53-deficient mice. J Nutr 2001;131Suppl 11:3092S-4S. 